

\title{
Workshop for innovation in the metropolises: urban mobility study of a university campus
}

Fernando Rodrigues Lima, Gilles Morel, Hipolito Martell-Flores, Nathalie Molines

\section{- To cite this version:}

Fernando Rodrigues Lima, Gilles Morel, Hipolito Martell-Flores, Nathalie Molines. Workshop for innovation in the metropolises: urban mobility study of a university campus. Proceedings of the ICE - Municipal Engineer, 2020, 173, pp.98 - 110. 10.1680/jmuen.18.00027 . hal-02992202

\section{HAL Id: hal-02992202 \\ https://hal.science/hal-02992202}

Submitted on 6 Nov 2020

HAL is a multi-disciplinary open access archive for the deposit and dissemination of scientific research documents, whether they are published or not. The documents may come from teaching and research institutions in France or abroad, or from public or private research centers.
L'archive ouverte pluridisciplinaire HAL, est destinée au dépôt et à la diffusion de documents scientifiques de niveau recherche, publiés ou non, émanant des établissements d'enseignement et de recherche français ou étrangers, des laboratoires publics ou privés. 


\section{Workshop for innovation in the metropolises: urban mobility study of a university campus}

\author{
Fernando Rodrigues Lima DSC \\ Full Professor, Federal University of Rio de Janeiro, Rio de Janeiro, \\ RJ, Brazil \\ Gilles Morel \\ Professor and Researcher, Université de Technologie de Compiègne, \\ Compiègne, France (Orcid:0000-0002-4432-2402)
}

\author{
Hipolito Martel-Flores \\ Professor and Researcher, Université de Technologie de Compiègne, \\ Compiègne, France (Orcid:0000-0003-4898-6764) \\ Nathalie Molines \\ Professor and Researcher, Université de Technologie de Compiègne, \\ Compiègne, France
}

This paper presents the project management of a transnational workshop in urban engineering, held as education and training for students from Brazil (UFRJ - Universidade Federal do Rio de Janeiro, Rio de Janeiro Federal University, Universidade Estadual de Maringá, Maringá State University) and France (UTC - Université de Technologie de Compiègne, Compiègne University of Technology, Sorbonne University). The aim was to encourage them to propose transport management improvements to the Cidade Universitária campus of UFRJ. Coordinators and students visited UFRJ and UTC to analyse data and develop solutions. The research methodology employed information technology - particularly geographic information system and collaborative platforms - in the documentation and communication. The findings were consolidated in two workshops, one at each university, and were later circulated through a webpage and final project report. A system diagnosis was produced, along with several short-, medium- and long-term proposals for internal mobility and connections with the existing urban transport network.

\section{Introduction}

This paper presents a teaching and research project conducted by an international professors' team with undergraduate students by way of exchange between two international partners in urban engineering: Universidade Federal do Rio de Janeiro, Rio de Janeiro Federal University (UFRJ) and Université de Technologie de Compiègne, Compiègne University of Technology (UTC). The research focus was urban mobility, while the teaching portion proposed academic innovation in that it engaged in practical activities relating to the profession, fostered networked collaboration and employed advanced digital tools.

The workshops for innovation in the metropolises (Les Ateliers de l'Innovation pour les Métropoles, AIM - Workshops in Innovation for the Metropolises, title of a project conducted as part of an 'Atelier Projet') (UFRJ and UTC, 2015) is a project sponsored by Sorbonne University, a group of which UTC forms part. Université Paris-Sorbonne (Paris IV) also participated in the project through UFR Geographie (Geographie unit of Université Paris-Sorbonne (Paris IV) directed to applied social sciences), bringing an important applied social sciences approach to the subject of technology. The topic, 'A Study to Draw Urban Mobility Scenarios for the Cidade Universitária Campus of Rio de Janeiro Federal University (UFRJ)', was chosen as part of that project. In exploring this internationalisation, AIM operated as a transnational projects workshop.
At UFRJ, urban engineering is offered as a subject only at the postgraduate level, while at UTC it is from the undergraduate to doctorate levels. AIM thus involved students on these related courses in Brazil and in France. On the one hand, the UFRJ Polytechnic School (Escola Politécnica, POLI), with its masters' programme in urban engineering (PEU (Programa de Engenharia Urbana - UFRJ Urban Engineering Programme)/POLI (Escola Politécnica - Polytechnic School, UFRJ)) and undergraduate programmes in civil and environmental engineering and, on the other, the UTC, with its undergraduate and doctoral programmes in urban systems engineering (GSU - Génie des Systèmes Urbains, UTC Department of Urban Systems Engineering).

The UTC students' participation was included in their curriculum through the project workshop (Atelier Projet, AP - project workshop: a discipline with a project pilot office for UTC undergraduates), a required subject, including hands-on activities through a pilot office, while the UFRJ students participated by way of the introduction to scientific method (IC - Iniciação Cientifica, Introduction to Scientific Method: a curricular activity at UFRJ that receives students at its research laboratories) discipline, a modality where students gain course credits for research and development activities. For the preparation of students' works two UTC's students developed their 6-month internship at UFRJ as responsible of contacts between student's teams and external partners; coordinators of 
students' teams at UTC and UFRJ exchanges, and in following a good execution of works planning.

The AIM project approach was multidisciplinary and systemic, allocating students from differing backgrounds, approximating teaching to professional practice and integrating various fields of knowledge. It also provided students with experience in new methods and techniques (e.g. geographic information system (GIS), network analysis, multicriteria analysis) and in collaborative platforms (e.g. Alfresco, Google Drive, Skype, WebGIS). That initiative thus addresses the issues raised by Bather (2011) on engineering students' role given the speed of innovation and their posture in calling for activities relating to professional practice, meeting new challenges and participating in initiatives that will later benefit their formation as future engineers.

\section{Study object}

The topic of internal urban mobility and accessibility of the UFRJ's Cidade Universitária campus was chosen in response to several factors. The campus in question is on an island approximately $5 \mathrm{~km}$ long $\times 1.5 \mathrm{~km}$ wide, the access bridges to which also serve as Rio de Janeiro's main expressways
(Figure 1). It houses around $80 \%$ of all UFRJ's activities, in addition to a university hospital, three major research centres (CEMPES, CEPEL and CPRM) and a technology park. All these installations draw a floating population estimated at nearly 60000 .

Although less than $8 \mathrm{~km}$ from Rio de Janeiro city centre, the campus is located in a region of already quite congested traffic; its internal roads are used as shortcuts at rush hours and do not offer good options for either access by public transport or internal movement (Figure 2).

The UFRJ Campus Administration (PU - Prefeitura Universitária/UFRJ) needed studies and proposals in order to improve the mobility situation and also to assist in future review of the UFRJ Master Plan (Plano Diretor da UFRJ (UFRJ, 2011)). It not only supported the project, but working together with the AIM team - specified mobility demands and priorities for the campus. The other campuses are distant and account for much smaller proportions of the UFRJ population (students, faculty and service personnel) and so were not contemplated in this study, mainly due to time and logistics constraints.

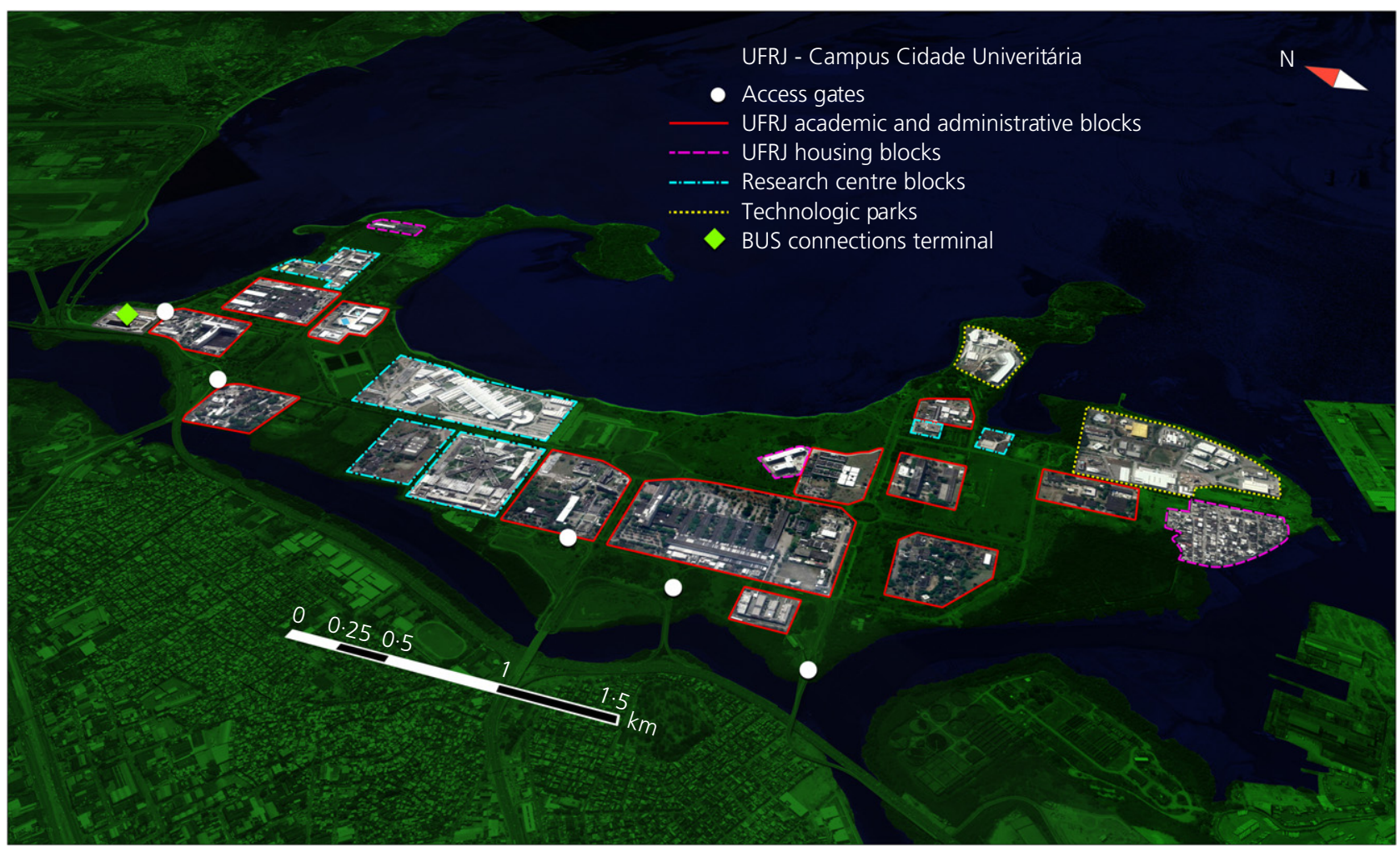

Figure 1. Cidade Universitária Campus, UFRJ: the island (source: Google Earth. A full-colour version of this figure can be found on the ICE Virtual Library (www.icevirtuallibrary.com)) 


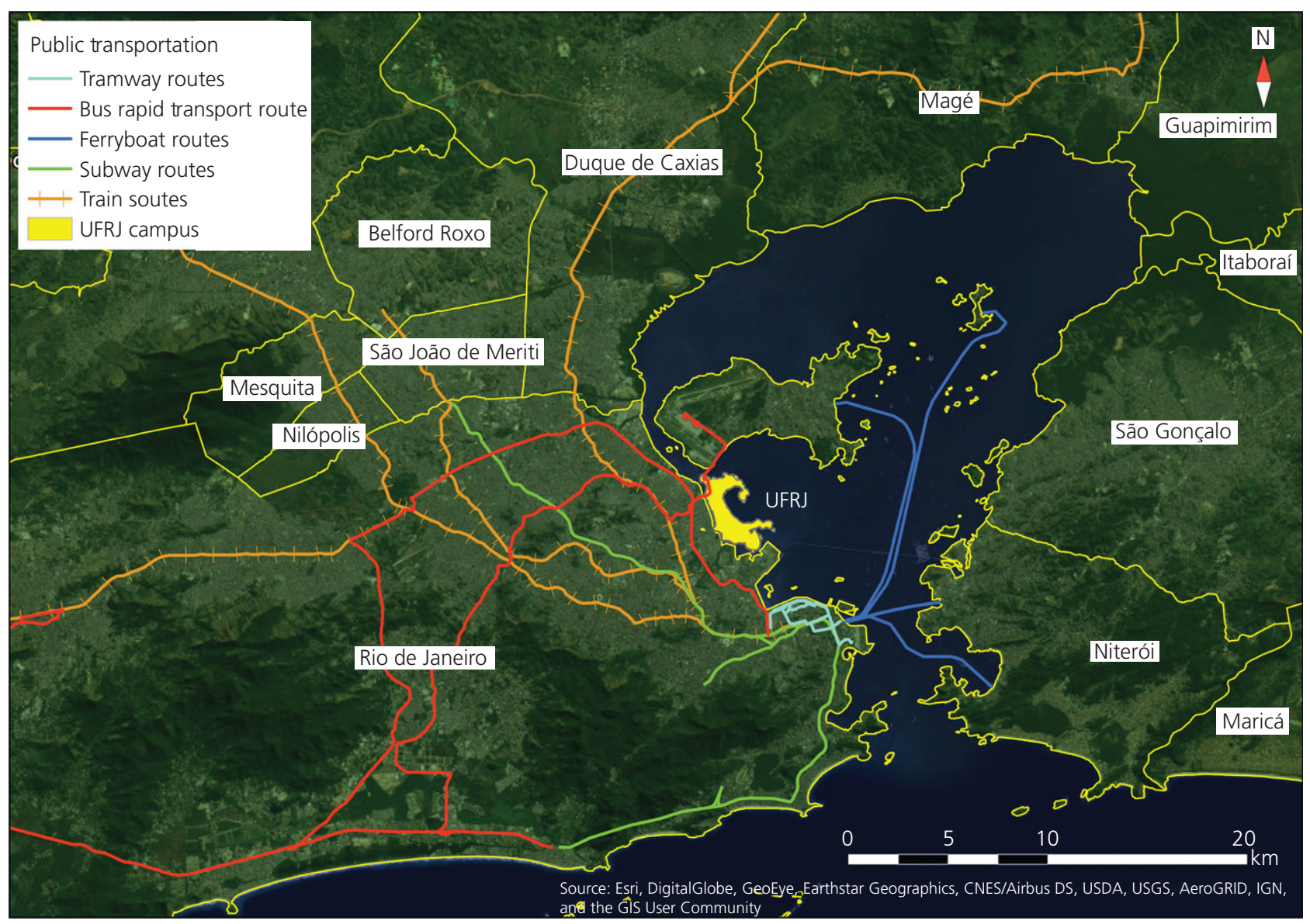

Figure 2. Screen print of campus location and public transport access routes (source: Authors' GIS. A full-colour version of this figure can be found on the ICE Virtual Library (www.icevirtuallibrary.com))

This contrasts strongly with the city of Compiègne in France, where the UTC is established on two campuses that are very close together (about $2 \mathrm{~km}$ apart) and perfectly integrated into a free public transport system consisting of buses that are monitored in real time and operated to regular timetables. Even once the scales of the two cities and the diversities between them are so distinct, it was still challenging for the French students to understand the situation at the UFRJ, formulate diagnoses and propose alternatives. It was also to be a rewarding experience for the UFRJ students to observe, record and discuss the information on their day-to-day mobility with their UTC colleagues, but now from the urban engineering standpoint.

The AIM undertaken here also contributes to the 'Living Laboratories' concept, which has been well explored in a collection of articles organised by König (2013) on the important role of such initiatives in cities and universities, where the local environment is used as experimental site for sustainable development. This trend towards turning university campuses into laboratories for teaching and research is also a way of returning the knowledge obtained there to the benefit of the university community itself and the population of neighbouring areas.

Several studies are developed worldwide regarding campus mobility and sustainable, innovative and participative solutions. Balsas (2003) had studied eight different campuses in the United States that adopted initiatives under this way, especially considering the bicycle and pedestrian planning point of view, considering them a very distinct milieu, but capable to replicate good practices and reshape society with good transportation patterns. The elements that influence transport decisions and shifts behaviour on campus community could be found in a study at University of Western Australia (Shannon et al., 2006), which presents useful results for elaborate future policies on mobility. Another interesting recent study was developed at the metropolitan campus of the 
Autonomous University of Barcelona (UAB), where authors (Soria-Lara et al., 2017) analyse how factors influenced the choice of car travels to campus using the '3Ss' approach (spatial location, socioeconomics and social behaviour) and produced a statistical correlation data to contribute to future elaboration of integrated transport policy packages.

\section{Techniques and methods}

AIM's innovative approach is reinforced even more strongly by the use of computer-aided design (CAD) tools and collaborative platforms. Prominent among the assisted design tools was the GIS platform for mapping overall campus infrastructure, demographics and mobility, and building up a georeferenced database that could be used by the whole team - for example, by way of web services (Figure 3). Using these methods and techniques aligns with the concept of applied geographic intelligence, which is now used in engineering and is also being deployed for professional practice (Cereda Jr., 2017a, 2017b).
Prior studies, such as Walles (2012), on GIS applications directed to promoting sustainability in the built-up environment, and Dailey and Stockton (2012), detailing methods and techniques for GIS modelling on campuses and related installations (both using ESRI's ArcGIS platform), encouraged the authors of this paper to develop their own methodology. The maturity achieved in the GIS environment was due mainly to team members' having participated in previous projects that employed this resource, more details could be found in Lima (2017), Morel et al. (2009, 2014) and Molines and Henriot (2017a, 2017b).

The experience accumulated in all these projects helped both to specify the methodology to be adopted in the AIM and to spread the GIS methods and techniques fast among new team members. Of particular note, one previous project mapped the UFRJ campus infrastructure (Lima et al., 2015): in addition to entering official data into a preliminary portion of the AIM GIS database, it also allowed subsequent consistency

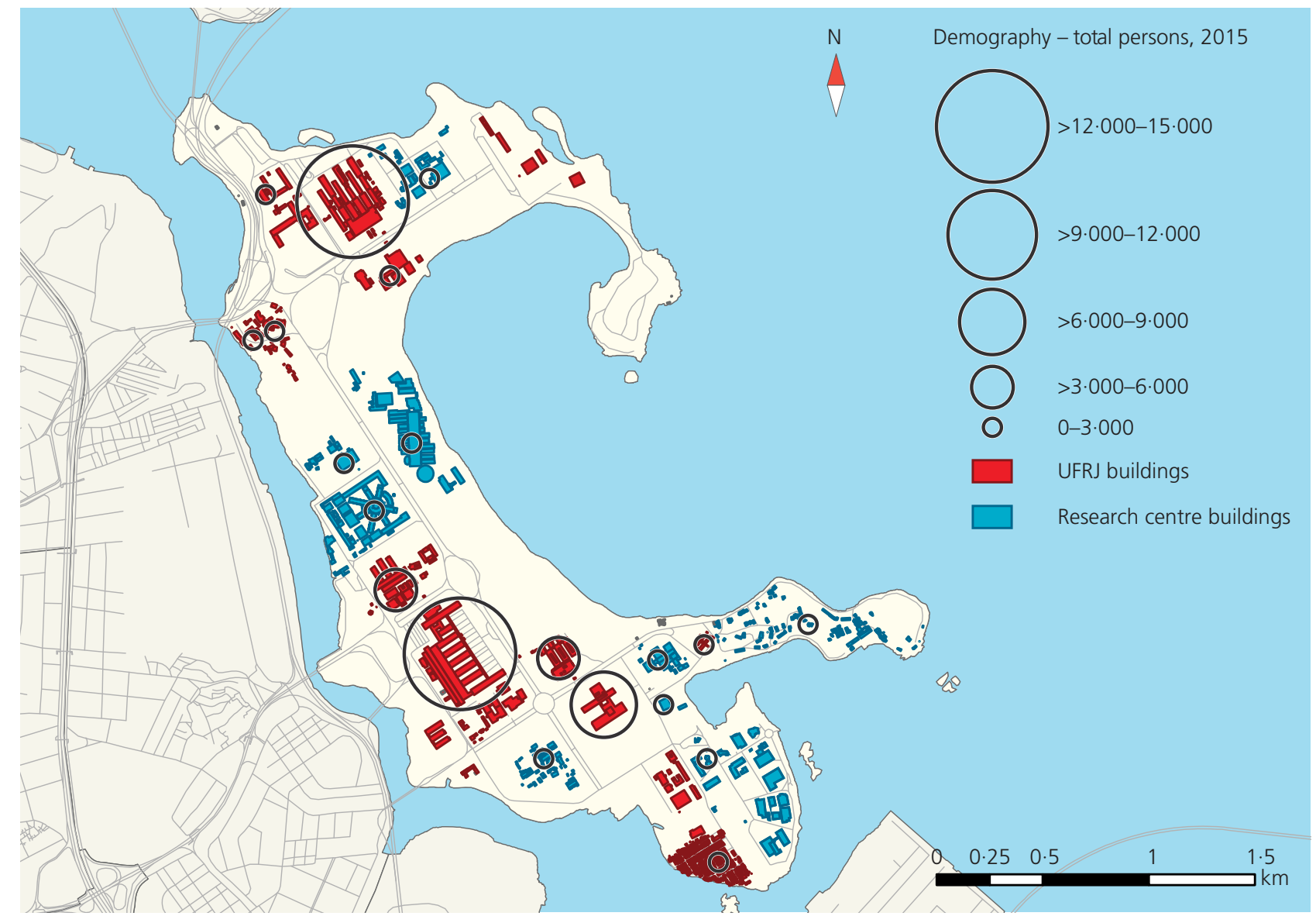

Figure 3. Screen print from WebGIS digital map, showing the database layers for the road system, buildings and demographics (source: Authors' GIS) 
verification of responses to the questionnaire applied by the AIM and simulation of the solutions proposed. The maps and digital data produced before and during the AIM can be consulted at SIGEUrb (2018).

In addition to the GIS resources already mentioned, the collaborative networked process used documents and files stored and shared on Google Drive, Alfresco and Skype for video conferencing and online computer screen sharing. By applying GIS methods and techniques and collaborative platforms, the AIM aligns with the 'Smart Cities' concept, in that it promotes the use of information technologies for sustainability, economy and wellbeing. Also in line with this concept, the AIM operates as a 'civic laboratory' (Townsend et al., 2011) to influence relations between the social body of the UFRJ and mobility services. Although 'Smart Cities' is more directly connected with urban control, automation and rationalisation routines by way of sensors, networks and web applications, Townsend et al. (2011) also argue that it can go beyond that initial functionality, to support more inclusive management of services and infrastructure for the citizen, thus expanding the application of applied geographic intelligence to the economic, social and environmental dimensions.

\section{Objectives of the international workshop and project}

The AIM project had an intermediate goal, which was to hold a transnational (French-Brazilian) project workshop, and a final and technical goal, which was to solve campus mobility problems. Both goals had to be achieved within a scope compatible with the students' academic level and consequent analytical potential and ability to produce results, without forgetting the transnational characteristics.

It was in this way that the students were afforded the experience of an 'hands on' activity intrinsically connected with their day-to-day living (in the case of the Brazilians) or which (in the case of the French members) addressed a new challenge. Even with clearly defined goals, bringing students from different cultures and languages into contact is not an easy task, not just for reasons of communication, but also due to the different focuses resulting from the curricular structures of their courses.

When the methodology of this AIM was applied to achieving the main goals, certain complementary goals were also set

Enable the students early experience in project management - that is, obtaining and organising data on the campus infrastructure and transport systems, users and managers.
- Develop databases by organising the information so obtained and the modelling of the urban mobility elements in a GIS environment.

- Apply and tabulate a questionnaire on the subject of mobility on the campus, so as to profile the users, their perceptions and demands.

- Organise and hold two thematic workshops, one in Brazil and the other in France, thus enabling the students to work on tasks for technical and scientific events.

- First, develop students grasp of the engineering decision-making process, by their adjusting methods and techniques, evaluating the data obtained to understand the main mobility problems and to establish a realistic diagnosis. Second, produce alternative solutions to the island accessibility and campus, and, finally, produce internal mobility solutions with their respective infrastructures' proposals.

- Leave a legacy for future students and the institutions involved, by setting up a project website, preparing a technical report with diagnoses and proposals and producing multimedia support material.

\section{The AIM}

In the first phase, the AIM addressed the issues of teambuilding capacity (mostly for students in mid-course), execution timeframe (one semester for preparation and another for completion) and logistical feasibility (travel costs and resources for putting projects into practice). At the same time, as students were expected to be able to organise themselves and manage tasks among the teams based at the UFRJ and UTC, the professors who coordinated the project endeavoured to keep them focused within the concepts of academic innovation, transnational workshop, collaborative platform and pilot office.

The idea of setting up the AIM arose at a preliminary stage when the UFRJ, Paris IV and UTC coordinators met several times to prospect the subject and develop a project proposal. After submission and institutional approval, the total AIM duration was set at 1 year, the first semester devoted to project planning and collection of data about the UFRJ campus, and involving a smaller team, while the second semester was spent on project execution and conclusion with the whole team.

The AIM structure was designed on the basis of an existing UTC discipline, the project workshop (AP) mentioned above. The GSU/UTC has held about six APs per year for at least the past 15 years, each involving around 20 students working as a team, $1 \mathrm{~d}$ per week, in partnership with a company, a local community or a state service, on a real or prospective project. These APs have addressed very diverse subjects (planning, transport, energy etc.), but always in connection with key 
urban issues. At the UFRJ, as already mentioned, undergraduate students were attracted by calls for interest by way of the basic scientific method (Iniciação Cientifica, IC) introduction to research programme. Some master's and doctoral students also took note of this call and joined the project. In order to orient demand for the project and its outcomes, the PU/UFRJ participated, represented by the administrator himself, who made personnel and data available and was present at AIM team meetings.

The AIM project execution stages were organised in the following sequence

(a) Choose and define the issue and site to be studied, in order to submit a proposal to be approved by the project funding agencies and university bodies involved.

(b) Hold meetings to launch the project, with a view to forming the team, mobilising available funding, identifying data sources and specifying the digital tools to be used in technical and internal communication applications.

(c) Organise and coordinate the work, listing tasks and arranging teams, timeframes and functions. At this stage, it is important to establish the degrees of autonomy of the various sub-groups and how they are to communicate and collaborate.

(d) Manage the project, applying digital tools to data collection, organisation and preliminary analysis and establishing communication channels using web resources.

(e) Diagnose the present mobility situation on the campus on the basis of the data collected, the users and managers interviews, and the use of digital tools and tabulation of questionnaire responses. This stage prioritises typical engineering methods (e.g. origin/destination matrix and model) and communication tools applied in such a way as to maintain the core endeavour of networked international collaboration.

( $f$ ) Propose alternative solutions to the mobility problem. Among the suggestions presented, some were short term, some medium term and others long term. These will all be detailed in the next section.

( $g$ ) Finalise the project, including workshops, updating of website content and presentation of a technical report to publicise the findings.

The roles (tasks and interactions) of each of the AIM team members also had to be specified. In this division of duties, the UTC students, whose backgrounds are more specifically in urban engineering and who were grouped in a much larger team (about 20) with a fixed curricular timetable, were tasked with analysing the data and proposing alternative responses.
The UFRJ students (about eight), meanwhile, whose academic backgrounds and levels were more diverse and who were under greater time restrictions, would be more efficient working on data collection and organisation and clarifying the doubts of the French students. As there were visiting students at both universities, the coordinators took advantage of the fact for some of them to manage the connection between the teams, so that there was always a Brazilian responsible (UFRJ and UEM - Universidade Estadual de Maringá, Maringá State University, Brazil) for this function at the UTC, a French counterpart at the UFRJ and another from the UFRJ at Paris IV.

In order for the French students to be able to absorb the physical realities of the UFRJ campus, it was essential to develop a database in GIS containing digital thematic maps (Figure 4) accessible by WebGIS (SIGEUrb, 2018). With that database it was possible to consult and analyse information on campus's demography, general infrastructure, access by public transport and internal movement. Photographic and descriptive coverage of campus internal mobility components (bus stops, road signing, hazards etc.) was also compiled.

In order to complement the database further, a questionnaire on users' travel, profiles, expectations and ideas was applied and tabulated using a web survey platform, which was distributed by way of an institutional link of the UFRJ's Integrated Academic Management System (SIGA - Sistema Integrado de Gestão Acadêmica - Integrated Academic Management System), which elicited a significant number of responses (around 5200 surveys, a significant sample of the overall social body). Once the questionnaire survey was concluded, some of the data (e.g. respondents' origins and destinations) were also added into the GIS base. When the questionnaire respondents' density and location ('hot spot' technique) were compared with the overall population registered in the SIGA (Figure 5), the sample was found to be highly representative.

Another important issue was the role of the workshop coordinators, one each at the UFRJ and the UTC, who worked jointly with the students, without intervening directly in their tasks, but being careful to observe whether or not AIM's objectives were being achieved and whether the actions proposed were in accordance with the project timetable. In this kind of projects where students learn to manage the project by themselves, professors play a better role of 'coaches', advisers or experts, responding to the students' needs.

Two scheduled workshops were held to consolidate results, the first at the UTC to examine the preliminary results, and the other, at the UFRJ on conclusion of the project, attended by the UFRJ campus administrator and the head of 


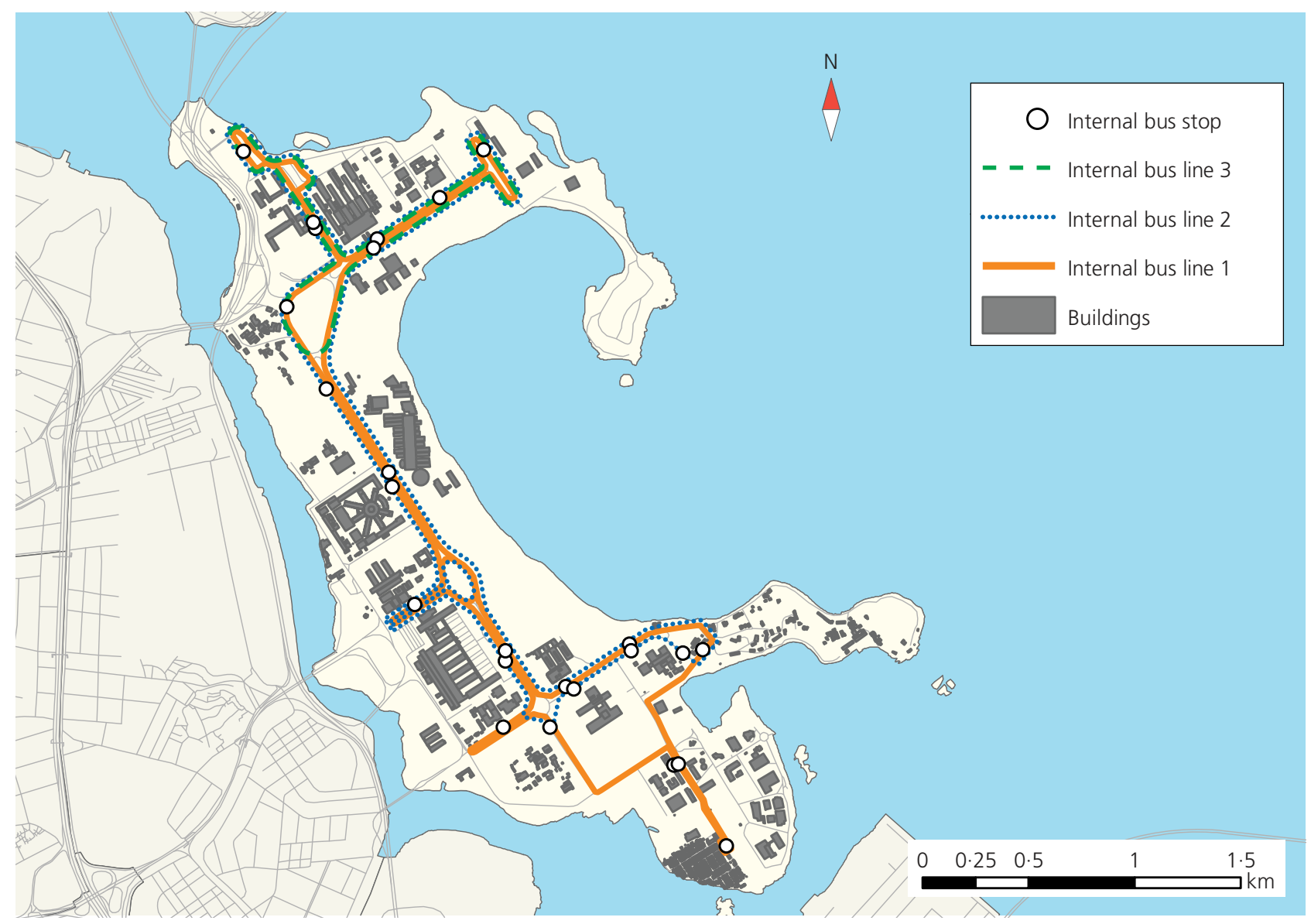

Figure 4. Screen print from WebGIS digital map, showing campus internal bus routes (source: Authors' GIS. A full-colour version of this figure can be found on the ICE Virtual Library (www.icevirtuallibrary.com))

the Rio de Janeiro State metropolitan management body (Câmara Metropolitana). An enormous amount of audiovisual material was also produced, including interviews of the campus administrator, mobility experts from the UFRJ and members of the Brazilian project team. Reports were produced continually on all stages of the project and were posted to a website (UFRJ and UTC, 2015) developed especially for the AIM.

\section{Results}

The results obtained for the improvement of the mobility in the UFRJ campus can be separated into two phases: diagnoses and proposals. A very large amount of data was presented in these two phases, which is why this section seeks to give an overview of those results. Further details can be found in the technical reports posted on the AIM website (UFRJ and UTC, 2015).
As mentioned earlier, the interviews, the development of the GIS base, the field visits and photographic coverage, the mobility questionnaire, the data organisation and analysis activities, all these instruments enabled both teams to interact towards developing a broad diagnosis of accessibility and internal mobility issues, which is summarised in Figure 6.

The complete diagnosis was presented in the final report, which addressed the following topics

- Conceptualisation of campus mobility and related factors: safety, sustainability, economy and efficiency.

- Present status of transport systems: transport infrastructure by mode (car, bus, bicycle and pedestrian), by category (public and private) and by cost (paid and free).

- Conflicts, stress and hazards in internal travel in conjunction with city traffic flows that pass through the campus. 
Lima, Morel, Martel-Flores and Molines

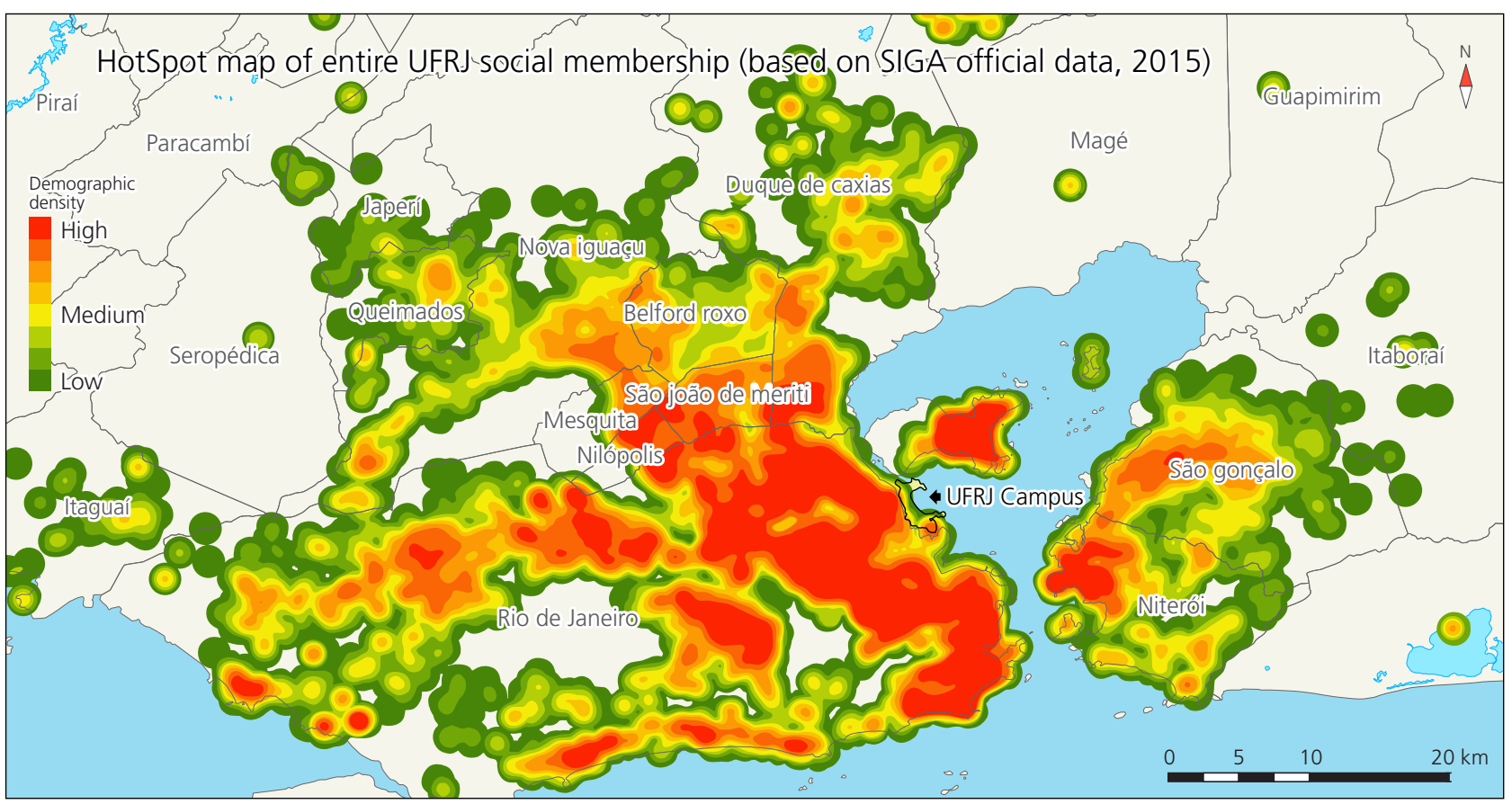

(a)

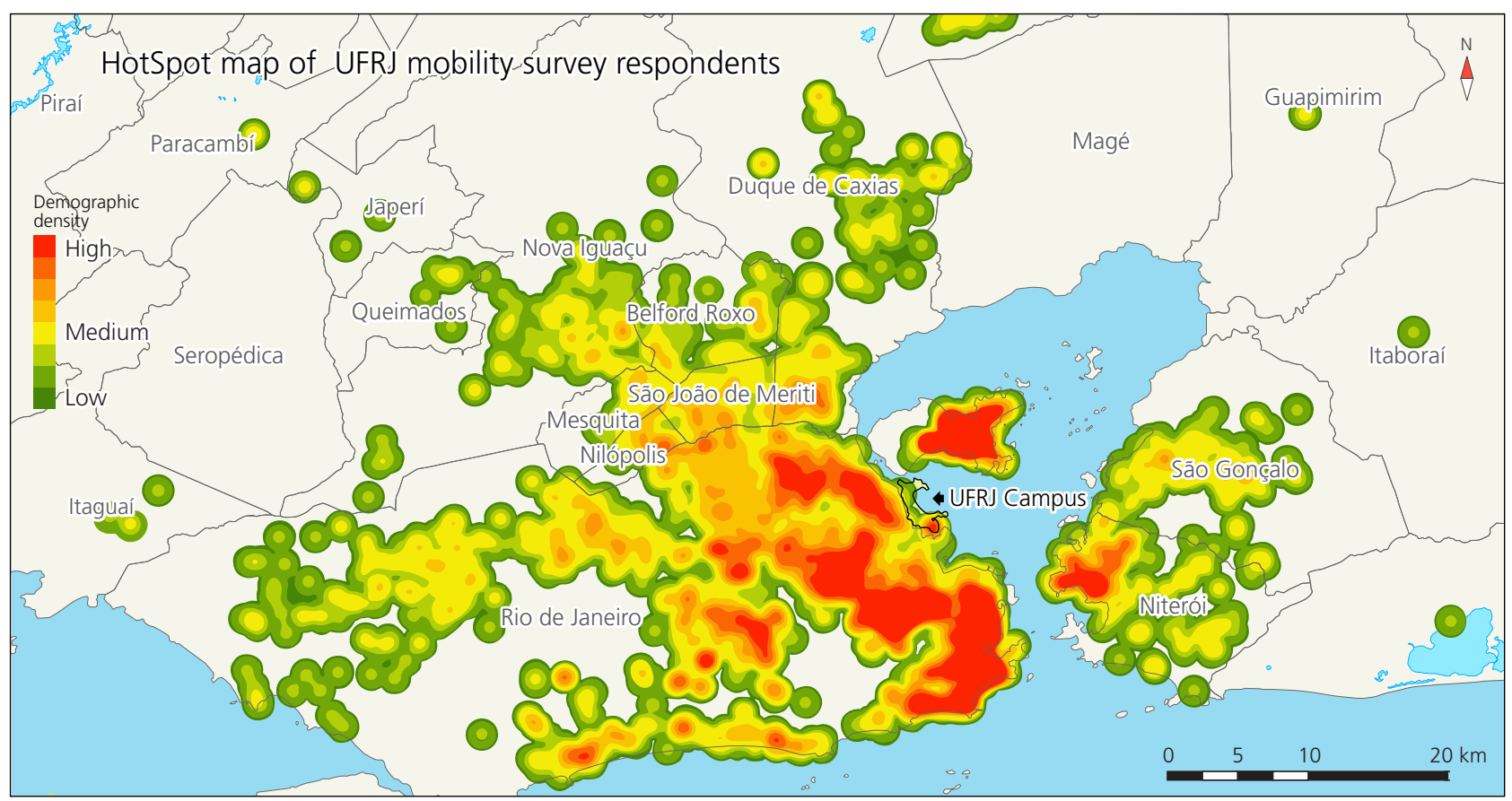

(b)

Figure 5. Screen print from WebGIS digital maps comparing densities (hot spots) of the social body (a) and questionnaire respondents (b) (source: Authors' GIS. A full-colour version of this figure can be found on the ICE Virtual Library (www.icevirtuallibrary.com)) 


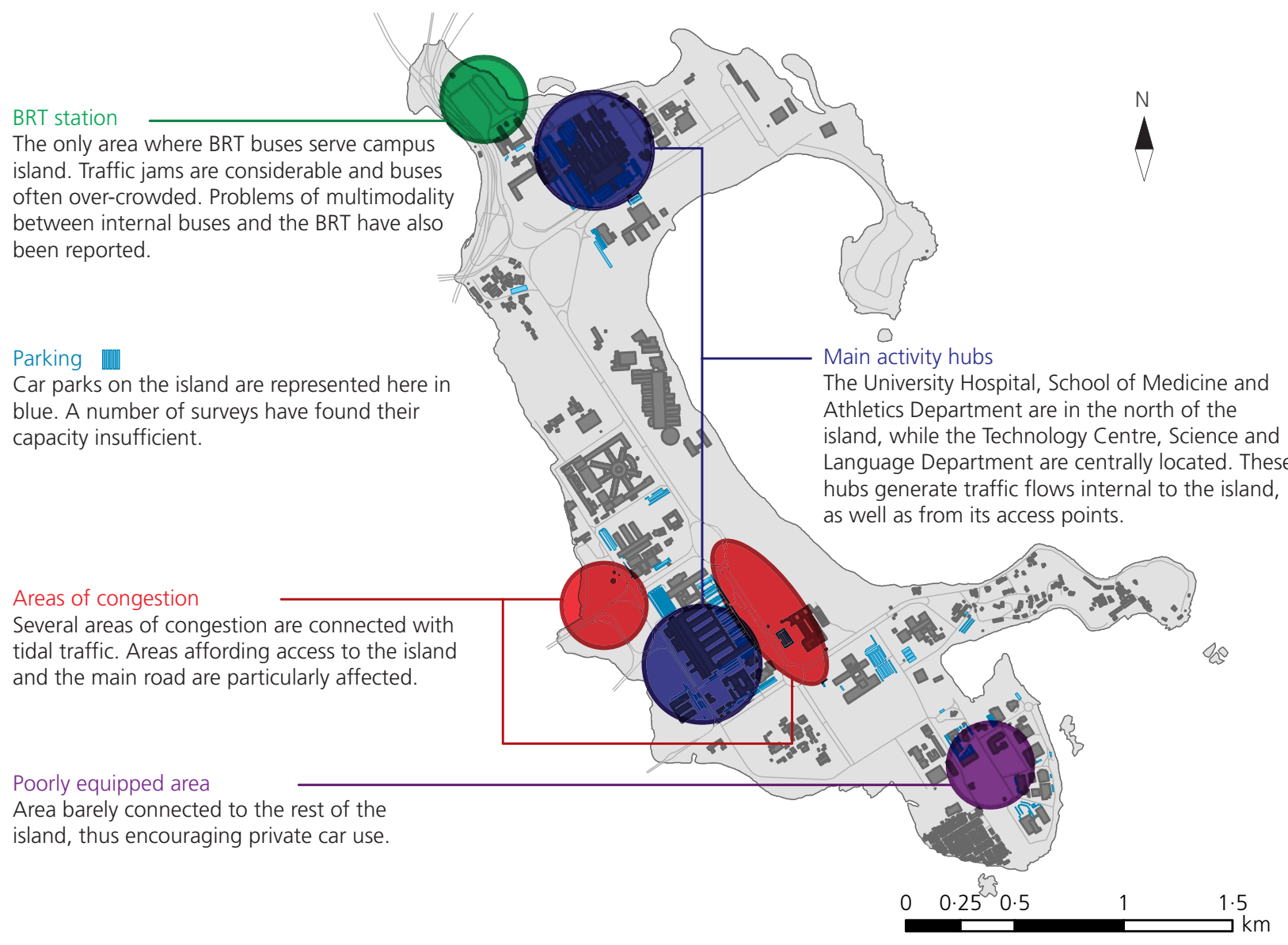

Figure 6. Summary diagnosis of the campus (source: Authors' GIS/AIM Final Report)

- Travel origins and destinations of the social body: students, professors and employees, their flows, frequency, times and modes of transport used in accessing the campus and in internal mobility.

- Evaluation of the UFRJ's current master plan (Plano Diretor (UFRJ, 2011)) and its intersections with external factors (municipal and state administration).

- A systemic analysis of the situation, taking into account multiple parameters such as different transport means, interrelation between them, users profiles and behaviour, enables to optimise and improve a modal repartition of the transport offer and choice, and a better balance between the different modes (individual car, buses, bicycles etc.).

This 'modal split' concept enhances the attractiveness of public transport and alternative travel means (pedestrian, bicycle and car sharing) and also encourages demand for reorganisation of internal flows and improvements in current services.
The proposals resulting from this diagnosis were projected and grouped into three time horizons: short-, medium- and longterm outlooks. For each proposal, a comparative system was developed on the basis of multicriteria analysis, and details could be found on the AIM final report.

The short-term outlooks considered proposals for

- Internal bus lines. To continue free of charge, reorganised routes, stops and timetables.

- Car sharing. Managed by web application, preferential parking for participating drivers and specification of meeting points.

- Bicycle. Wider use encouraged, with improved cycle parks, cycle tracks and safety.

- Better and new signings for pedestrians, cyclists, motorists and internal bus users: signposts, intermodal connections, crossings, colour coding and so on. 
The mid-term outlooks considered also alterations in the conditions of supply and circulation of internal and external buses

- Connection between the campus and the neighbouring municipality of Niterói, whose metropolitan region is home to a large part of the UFRJ social body, but lacks any direct bus lines to the campus.

- Installation of exclusive lanes for internal buses: designed to improve internal mobility at times when traffic flows from the city enter the campus and cause traffic jams.

- More thorough modification of internal bus timetables, routes and stops, based on the experience obtained on the spot by students during the short-term project timeframe.

- Expansion and improvements of internal lines to the existing bus terminal: sited at the north of the campus, the latter receives municipal express bus lines for transfers to and from internal buses.

- Restrictions on external buses: reorganise routes, reduce number of lines with access and restrict circulation to the proximity of the bus termini.

- Installation of a new terminal at the centre of the campus, with physical alterations to make it possible also to set-up a convenience area with bars and services, interfaces with parking, pavements and cycle tracks and so on, thus laying the bases for a multimodal hub.

- Introduction of new parking areas integrated with sustainable policies (sharing, use of internal bus services etc.).

The long-term outlooks considered alternatives that depend less on the university administration and more on interrelations with the municipal and state administrations, available budgets and financing, and, most importantly, on political will among policymakers.

These broader outlooks also include the option for a sustainable means of transport (tramway or maglev), which would run along the main north-south axis. There is already a municipal tramway serving the nearby Porto Maravilha neighbourhood, which would need to be extended by a few kilometres in order to reach the campus. The Cobra maglev, meanwhile, is a magnetic levitation vehicle project developed totally by the UFRJ, which is at the certification stage and has a 500-m pilot stretch already set-up.

There are two variants of long-term outlook, as summarised on the map in Figure 7. Regardless of the choice made between tramway and maglev, the installation and organisation of the other means of transport remains coherent. Mobility is fostered by introducing connections between the various means of transport and by developing multimodal hubs that include activities and services. In this long-term projection, the intention is to develop alternative modes of transport at these hubs and to transform a portion of the transversal avenue at the centre of the campus underground, so as to facilitate movement for pedestrians and bicycles. In the proposed collective transport circuits, multimodality displacements contemplate the possibility of bicycles, internal buses and the tramway or maglev combinations.

In this outlook, new, effective, sustainable means of transport (maglev or tramway) are introduced on an axis that integrates the isolated areas in the south of the island and affords the transport and service networks greater access to them. The items that make up the long-term scenario can be summarised as follows

- Comparative analysis of the tramway and maglev: the aim was to ascertain the feasibility of introducing a means of transport that was less polluting, economic, silent and, thus, sustainable.

- Installation of transport by cable car, which could first serve the internal needs of the campus and later be extended to areas such as the city centre and international airport.

- Redesign of the road structure, by building new raised thoroughfares to expand the area of the multimodal hub and segregate the flows of cars and buses from those of pedestrians and bicycles.

- Expansion and improvement of the bicycle system, at this stage allowing internal use of self-service bikes or integration with existing self-service bike systems.

- Waterway link: given the campus's location on an island in the central portion of Guanabara Bay, there is great potential for setting up stations for connections with the existing waterway system and for proposing new routes (Ilha do Governador, Botafogo, Icaraí and São Gonçalo).

Despite the differences between the students in language, background and academic progress, they achieved a feasible, concrete result for application, as documented in a 70-page technical report (UFRJ and UTC, 2015), which was approved by the UFRJ campus administration at the close of the second and final workshop.

\section{Conclusions}

Mobility studies produce best results when stakeholders listen to the users, and based on their wish list can achieve solutions that bring innovation close to sustainability. As in the study by Gonzalo-Orden (2012) on campus mobility at Burgos University (Spain) the solution was not limited to the technical aspects of solving flow problems. Similarly to what was done there, the AIM gathered data from university community daily journeys to produce proposals that considered user perceptions 


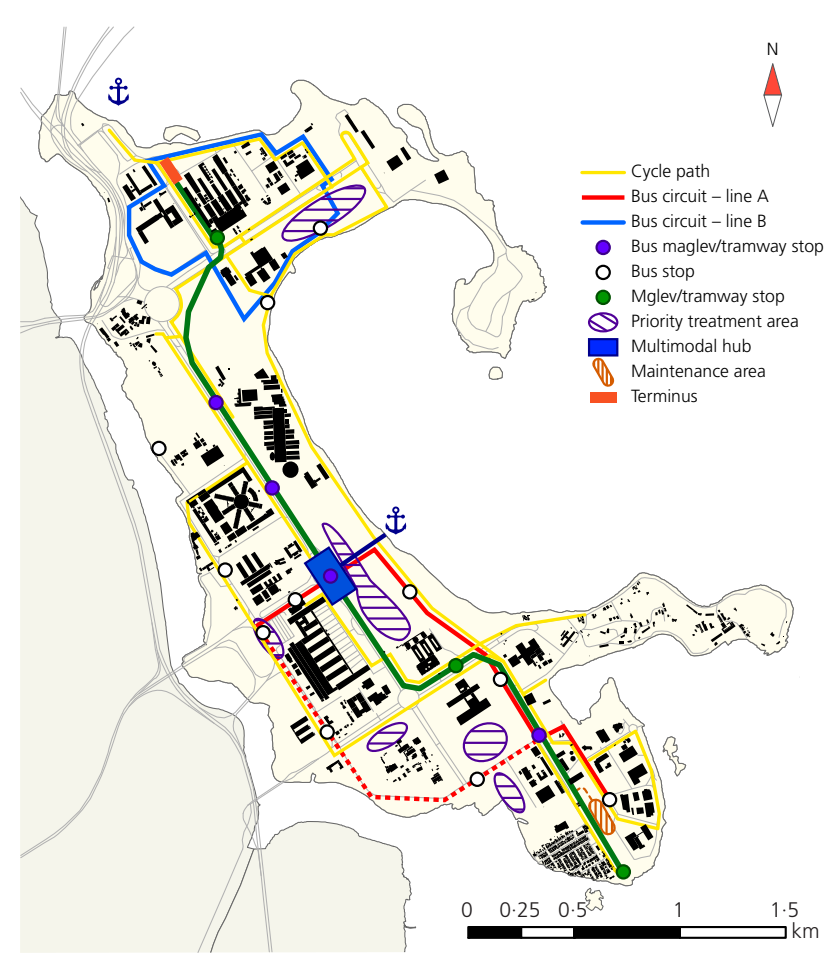

(a)



(b)

Figure 7. Summary maps of the two long-term scenario variants produced by the AIM, the right one differs from left one only at the internal bus circuits (source: Authors' GIS/AIM Final Report. A full-colour version of this figure can be found on the ICE Virtual Library (www.icevirtuallibrary.com))

and directed the results to sustainable policies, low energy consumption, low-emission options, in addition to recommending a spatial reordering of the campus.

In the course of the activities, some students were found to have more difficulty in coping with project management, partly because this discipline had not been addressed in these students' curricula prior to the AIM. However, this did not prevent them, by and large, from gaining cross-cutting 'metacompetences', which was one of the academic goals of this AIM. Experiencing a situation where they practised professional engineering, using multicriteria methods and scenario evaluation, enabled these students to explore new research and innovation activities.

The final outcomes can be positively evaluated in various approaches.

Educational. In three satisfied goals, primarily through the competences acquired by the students in the course of the project; the learning of engineering methods and tools for urban and transports analysis and solutions design and in project management skills.
- Operational. In the use of digital technologies and collaborative tools thanks to which outcomes were produced.

- Innovative. In results of the new technologies and innovation processes, how far the students really resorted to the techniques and methods proposed for problem solving and how far they used the collaborative platforms for information exchange and consolidation.

- Paradigm. In the project as a model, whether the AIM really established a methodological frame of reference for future international student project workshops.

By applying all the modes of evaluation above, the results can be said to have been achieved and found satisfactory. Obviously difficulties were encountered, but were surmounted thanks to the co-operation that has now existed for the past 6 years between the UTC and the UFRJ, which facilitated relations between the coordinators and enabled students to adjust themselves fast in international exchange.

In coming years, urban projects will increasingly integrate more data from sensors and connected objects, and GIS will have to evolve with technologies involving big data, the 
Internet of things (IoT) and artificial intelligence. Since 2016, the UTC has run multidisciplinary project workshops exploring connectivity in vehicles and buildings, and one of the future challenges will be to couple these new data with GIS platforms.

Meanwhile, university curricula have not yet completely absorbed the integrated project concept, and are not yet inserted in the 'Living Labs' concept (Konig, 2013). In general it can be perceived that a lack of disciplines designed to prepare students for involvement in projects and a need for more course time and credits to be allocated to undertaking these activities.

Finally, the authors' emphasise that transnational activities such as these allow

The share of competences and heterogeneous outlooks by students.

- The integration of professors' researches and knowledge to better integrate, form and consolidate international collaborative networks.

- The adjustment of institutional curricula to apply with an integrate view to professional practice, technological innovation and academic mobility.

The choice of a theme relating to sustainable cities, more specifically directed to sustainable urban mobility, offered the opportunity to explore the transverse nature of the disciplines involved, which were approached in this AIM within the context of the internationalisation of engineering teaching, academic innovation and professional training.

\section{Acknowledgements}

The authors are grateful to the Sorbonne University, as the AIM's main supporter, to CAPES (Coordenação de Aperfeiçoamento de Pessoal de Ensino Superior - Higher Education Personnel Improvement Coordination Office, Brazilian government funding agency)/MEC (Ministério da Educação e Cultura - Education and Culture Ministry of Brazil) by supporting BRAFITEC (Cooperação Brasil-França em Tecnologia - Brazil-France Cooperation in Technology: an undergraduate academic mobility teaching project that fosters exchanges between students from Brazil and France) and PVE (Pesquisador Visitante Especial - Special Visiting Researcher: a CAPES and CNPq (Conselho Nacional de Pesquisa - National Research Council, Brazilian government funding agency) project that fosters mobility among Brazilian and other university researchers) projects, to the UFRJ chief administrator (Paulo Mario Ripper), to the UFRJ deputy directorate for International Relations (DARI (Diretoria Adjunta de Relações Internacionais - International Relations Board
Assistant)/POLI/UFRJ), to our collaborators Professor Ricardo Manfredi Naveiro (DEM (Departamento de Engenharia Mecânica - Mechanical Engineering Department) /POLI and PEP (Programa de Engenharia de Produção Industrial Engineering Program)/COPPE (Coordenação de Programas de Pós-Graduação em Engenharia - Engineering Graduated Programs Coordination)/UFRJ) Professor Lino Marujo (DEI (Departamento de Engenharia Industrial Industrial Engineering Department)/POLI and PET (Programa de Engenharia de Transportes - Transportation Engineering Program)/COPPE/UFRJ) and Fabio Krykhtine (LabFuzzy/PEP/COPPE/UFRJ), as well as to all the AIM team at POLI/UFRJ, Paris IV and GSU/UTC.

\section{REFERENCES}

Balsas CJ (2003) Sustainable transportation planning on college campuses. Transportation Policy 10(1): 35-49.

Bather M (2011) Students' views on their education and the future. Proceedings of the Institution of Civil Engineers - Municipal Engineer 164(4): 209-219, https://doi.org/10.1680/jmuen.15.00038.

Cereda A, Jr. (2017a) Mapas, aplicativos móveis e a nuvem: Transformação Digital e as Engenharias. Revista Digital de Engenharia da APEAESP n. 3. See https://geografiadascoisas.com. br/artigos/mapas-aplicativos-moveis-e-a-nuvem-transformacaodigital-e-as-engenharias/ (accessed 05/11/2018) (in Portuguese).

Cereda A, Jr. (2017b) A. Inteligência Geográfica e a Transformação Digital: competências básicas na Gestão do Território alavancando oportunidades profissionais. Revista Digital de Engenharia da APEAESP n. 1. See https://geografiadascoisas.com. br/artigos/inteligencia-geografica-e-a-transformacao-digitalcompetencias-basicas-na-gestao-do-territorio-alavancandooportunidades-profissionais/ (accessed 05/11/2018) (in Portuguese).

Dailey G and Stockton S (2012) GIS in Education: Across Campuses, Inside Facilities. ESRI E-books, Redlands, CA, USA. See https://www.esri.com/library/ebooks/gis-in-education-facilities.pdf (accessed 05/11/2018).

Gonzalo-Orden H (2012) Mobility surveys and sustainable policies in universities. Proceedings of the Institution of Civil Engineers Municipal Engineer 165(4): 219-229, https://doi.org/10.1680/muen. 12.00014.

König A (ed.) (2013) Regenerative Sustainable Development of Universities and Cities: The Role of Living Laboratories. Edward Elgar Publishing, Cheltenham, UK.

Lima FR, Santos MVSM, Almeida MLR and Coelho RCS (2015) Base de dados elaborada numa plataforma SIG e direcionada para aplicações em 'Smart Campus'. In II Encontro Nacional de Tecnologia UrbanalV Simpósio de Pós-Graduação em Engenharia UrbanalII Simpósio de Infraestrutura e Meio Ambiente. UPF Editora, Passo Fundo, Rio Grande do Sul, Brazil, vol. 1, pp. 1226-1235 (in Portuguese).

Lima FR, Cosenza CAN and Das Neves C (2017) A hierarchical model for biodiesel plant location in Brazil. Proceedings of the Institution of Civil Engineers - Energy 170(4): 137-149, https://doi.org/10.1680/jener.16.00023.

Molines N and Henriot C (2017a) Apports et limites de la thermographie aérienne comme outil de diagnostic de la performance énergétique d'un parc résidentiel. Exemple de l'agglomération de Compiègne. Revue Internationale de 
Géomatique 27(1): 37-63, https://doi.org/10.3166/rig.2017.00020 (in French).

Molines N and Henriot C (2017b) Aerial thermography as a diagnostic tool for residential building stock energy assessment, within a local energy policy perspective. Proceedings of 3rd Energy for Sustainability International Conference - Designing Cities \& Communities for the Future, Funchal, Portugal.

Morel G, Hissel F, Aunay S and Demotier S (2009) OSIRIS-Multirisques: une méthode et un outil d'aide à la décision pour les communes soumises aux risques majeurs. Revue Européenne, $\mathrm{http} / / /$ doi.org/10.4000/cybergeo.22447.

Morel G, Pescaroli G, Graaf H, Felts D and Pietrantoni L (2014) Early warning and mass evacuation. Coastal Engineering 87: 193-204.

Shannon T, Giles-Corti B, Pikora T and Bulsara M (2006) Active commuting in a university setting: assessing commuting habits and potential for modal change. Transport Policy 13: 240-253.

SIGEUrb (Laboratório de Sistemas de Informação Geográfica Aplicados à Engenharia Urbana) (2018) http://sig-peu-ufrj.maps.arcgis.com/ home/index.html (accessed 15/05/2018).

Soria-Lara JA, Marquet O and Miralles-Guasch C (2017) The influence of location, socioeconomics, and behaviour on travel-demand by car in metropolitan university campuses. Transportation Research Part D 53: 149-160.

Townsend A, Maguire R, Liebhold M and Crawford M (2011)

A Planet of Civic Laboratories: the Future of Cities,

Information, and Inclusion. Institute for the Future (IFTF), Palo Alto, CA, USA. See http://www.iftf.org/our-work/globallandscape/cities/the-future-of-cities-information-and-inclusion/ (accessed 05/11/2018).

UFRJ (Rio de Janeiro Federal University) (2011) Plano Diretor da Cidade Universitária, Superintendência Geral de Comunicação Social (SGCOMS). UFRJ, Rio de Janeiro, Brazil (in Portuguese).

UFRJ and UTC (2015) AIM - Ateliers de l'Innovation pour les Métropoles. Final report. GSU/UTC, Compiègne, France. See http://aim.poli.ufrj.br/index.php/final-reports-available-onfrench-and-portuguese-versions/ (accessed 05/11/2018) (in Portuguese and French).

Walles P (2012) The Role of GIS Technology in Sustaining the Built Environment. ESRI E-books, Redlands, CA, USA. See https://www.esri.com/library/ebooks/sustaining-the-builtenvironment.pdf (accessed 05/11/2018).

\section{How can you contribute?}

To discuss this paper, please email up to 500 words to the editor at journals@ice.org.uk. Your contribution will be forwarded to the author(s) for a reply and, if considered appropriate by the editorial board, it will be published as discussion in a future issue of the journal.

Proceedings journals rely entirely on contributions from the civil engineering profession (and allied disciplines).

Information about how to submit your paper online is available at www.icevirtuallibrary.com/page/authors, where you will also find detailed author guidelines. 